\title{
A CRÍTICA BRASILEIRA DE POESIA CONTEMPORÂNEA: VELHOS DEBATES, OUTRAS MÁSCARAS
}

\author{
BRAZILIAN CONTEMPORARY POETRY CRITICISM: \\ OLD DEBATES, OTHER MASKS \\ Susana Scramim \\ Universidade Federal de Santa Catarina \\ Florianópolis, SC, Brasil
}

PALAVRAS-CHAVE: Poesia brasileira contemporânea; crítica literária; Carlito Azevedo; lumna Maria Simon.
KEYWORDS: Brazilian contemporary poetry; criticism; Carlito Azevedo; lumna Maria Simon.

PALABRAS LLAVE: Poesía brasileña contemporánea; crítica literaria; Carlito Azevedo; lumna Maria Simon.

\section{Resumo}

Propóe-se com este artigo refletir tanto sobre a produção poética quanto a sua crítica, tanto sobre a história da poesia quanto da história da crítica. Elas não são discutidas como instâncias separadas, mas, ao contrário, serão tomadas como práticas de uma mesma teoria/pensamento sobre a arte. A crítica de poesia contemporânea no Brasil tem que enfrentar alguns desafios propostos pelo modo de se produzir poesia no presente. No lugar de impor as mesmas exigências e cobranças das práticas críticas idealistas e utópicas à poesia e de responder com paráfrases de velhos debates aos desafios do presente, a crítica tem diante de si a poesia a tarefa de também tentar elaborar sentidos para a cultura do contemporâneo, o que implica sempre uma relação de interpretação com o passado e com a tradição. Longe de ser diagnosticado como um processo de "retradicionalização", "formalização" e "esteticização" dos problemas da cultura, a produção de poesia produz uma análise do tempo presente tão ou mais eficaz do que vem atribuindo-lhe certos setores da crítica.

\section{Abstract}

This paper aims at reflecting on the Brazilian poetic output and its criticism, taking into account their histories. They are not treated as separate instances, but instead are considered to be the result of practices issuing from a common theory of Art. The starting point of the discussion is an article by Iumna Maria Simon and Vinicius Dantas, "Negativo e ornamental: Um poema de Carlito Azevedo em seus problemas", published in Novos Estudos do Cebrap, n.91, Nov. 2011

\section{Resumen}

Este artículo se propone a discutir sobre la producción poética y su critica, sobre la historia de la poesía y de su critica. No se va a discutirlas como instancias aisladas, pero, al revés, serán tomadas como prácticas de una misma teoríalpensamiento sobre el arte. Toma-se como eje para la discusión el artículo de Iumna Maria Simon y Vinicius Dantas, "Negativo e ornamental: Um poema de Carlito Azevedo em seus problemas", publicado en la revista Novos Estudos do Cebrap, n.91, nov. de 2011. 
Adolf Loos e eu, ele literal e eu linguisticamente, nada mais fizemos que mostrar que entre uma urna funerária e um penico existe uma diferença, e que só nessa diferença há espaço para a cultura. Mas os outros, os positivos, se dividem entre aquele que usam a urna como penico e aqueles que usam o penico como urna. ${ }^{1 *}$

Um dos mitos que foram construídos no decorrer da história da crítica de arte é o de que existe a possibilidade da elaboração de tipos, para os realistas, ou de arquétipos, para os primeiros românticos, munidos da função de indicar a normatividade de certos modelos. Eles se apresentam não como problemas relativos à forma artística, mas como solução. E inclui-se, nesses casos, a vida vivida exposta e refletida na obra de arte compreendida também como um mito da origem, como solução do problema artístico.

O número 91 da revista Novos Estudos, publicada em novembro de 2011, apresenta o artigo "Negativo e ornamental: um poema de Carlito Azevedo em seus problemas", escrito pela professora e crítica literária Iumna Maria Simon e pelo poeta, ensaísta e tradutor Vinícius Dantas.* A operação crítica colocada em prática ali acusa a poesia de Carlito Azevedo de ser espetáculo, textual ou imagético, sem referente na realidade, que sua experiência poética subjetiva se reduz ao recalque, contrapondo a esta mesma poesia uma autêntica poesia que, diferentemente, se imporia como manufatura de imagens e metáforas. Essa maneira de empreender um julgamento, esse modo de organizar os valores da poesia não deixa de recorrer a arquétipos e tipos, doadores de soluções, da crítica antiga. A crítica construiu, a partir e contra Goethe, uma tradição própria. Os mitos que a constituíram não cessam de configurar o espaço de embate dessa mesma tradição. Sabe-se que operação crítica moderna está diametralmente oposta à posição de Goethe, para quem a "criticabilidade" da obra de arte é uma empresa impossível, porque somente o artista estaria munido da intuição do arquétipo para poder fazer o juízo apodítico sobre as suas obras. Entre-

\footnotetext{
${ }^{1}$ No original: "Adolf Loos und ich, er wörtlich, ich sprachlich, haben nichts weiter getan als gezeigt, daß zwischen einer Urne und einem Nachttopf ein Unterschied ist und daß in diesem Unterschied erst die Kultur Spielraum hat. Die andern aber, die Positiven, teilen sich in solche, die die Urne als Nachttopf, und die den Nachttopf als Urne gebrauchen". Cf. KRAUS, Karl. "Die Zeit". In: Aforismen: Sprüche und Widersprüche; Pro domo et mundo; Nacht. Berlim, Directmedia, 2007.
}

* (KRAUS, Karl. Aforismos Renato Zwick (trad.). Porto Alegre: Editorial Arquipélago, 2010: 169.)

* (SIMON, Iumna Maria; DANTAS, Vinícius. "Negativo e ornamental: um poema de Carlito Azevedo em seus problemas". In: Novos Estudos. São Paulo: Cebrap, n. 91, novembro de 2011.) 
tanto, após o desdobramento da questão por Walter Benjamin, a crítica das obras não só é possível como é objetivamente necessária, só que essa mesma crítica, equiparada pelo filósofo alemão ao trabalho de elaboração das formas, produz suas próprias soluções míticas. Para esse Benjamin que escreve sua tese sobre o conceito de crítica de arte no romantismo alemão, tanto o conceito de forma como o conceito de crítica em Goethe são insuficientes para dar conta da tarefa que se antepunha tanto para a crítica como para a poesia romântica, mas ele compreendia também que nesses problemas residia ainda algo de muito urgente para a tarefa do crítico e da poesia no momento histórico, as primeiras décadas do século $\mathrm{XX}$, em que ele escreve e se propõe a trabalhar como crítico de arte e da cultura. Decorre dessa posição a "negatividade" da operação crítica proposta por ele, ou seja, a de lidar e questionar seu objeto sem nunca poder apropriar-se dele.

Quando a crítica contemporânea acusa a arte e a poesia de produzirem formas "fraquinhas de negatividade", ${ }^{2}$ aquilo que é cobrado nesse julgamento não são formas "fortes" da negatividade, e sim a origem da forma não como geradora de mais e mais questionamentos, mas antes, tomada em seus mitos, como doadora de soluções apaziguadoras em sua sistematização. Não quero dizer com isso que a prática intertextual promovida por Haroldo de Campos, como reivindicada por Iumna Simon em 2011, pudesse ser analisada como sendo uma forma forte de negatividade. Ao contrário, o que postulo é que a tradução compreendida como um novo original não escapa de operar uma reivindicação da propriedade legal do objeto. Portanto, a prática do intertexto não é suficiente porque seja fraca, mas sim porque ainda afirma uma positividade, e, com isso, o mito em seu desejo por sistematização. Nesse sentido, e por mais paradoxal que isso possa parecer, o que a crítica literária Iumna Simon cobra da poesia contemporânea é a mesma posição frente à obra vivida e reivindicada por Haroldo de Campos, seja na sua prática poética, seja na atividade da crítica.

Há uma urgência em se investigar a relação dos métodos dos quais se vale esta operação crítica, vale dizer, sua relação com o ideal de obra de arte pensado como aquele que é produtor de exemplari-

\footnotetext{
${ }^{2}$ Quando se refere à relação que o poeta Haroldo de Campos mantinha com a tradição, Iumna Maria Simon reduz essa relação a uma prática do intertexto e a julga como uma forma de negatividade. Cf. SIMON, Iumna Maria. "Condenados à tradição". In: Piauí, n. 61, outubro de 2011.
} 
dade e a partir do qual se produz uma forma original. A ideia de arte, seu conteúdo de verdade, é sistematizada por essa crítica romântica em um mito, um ideal: uma forma sistematizada. É importante ressaltar novamente: o problema não reside na observância do exemplo, e sim na reivindicação do original. Toda a prática da produção de cultura tem necessariamente de lidar com a história de cada área da cultura. A crítica não escapa a essa prerrogativa.

\section{Negativo e ornamental}

Em 1931, Walter Benjamin escreveu um ensaio sobre Karl Kraus, escritor e redator do jornal Die Fackel ("A tocha"), que viveu em Viena praticamente durante toda sua vida e foi, antes de tudo, um grande polemista, inflexível e radical. No ensaio, Benjamin destaca que, à semelhança de outro polemista contemporâneo seu, Adolf Loos, autor do ensaio Ornament und Vebrechen, ${ }^{3}$ cujo objetivo principal é oferecer as bases para uma crítica à corrupção de uma sociedade materializada no ornamento, Kraus entendia a cultura do ornamento como um dos sintomas da doença crônica que era propagada especialmente pela imprensa: a inautencidade. Não devemos esquecer-nos que Kraus também escreveu, em 1908, Sittllichkeit und Kriminalität ("Moralidade e criminalidade"), dando-nos uma pequena dimensão do efeito que seus escritos polêmicos tinham em sua sociedade. Walter Benjamin fala da "interação estranha entre a teoria reacionária e da prática revolucionária que é cumprida em todo Kraus".* De acordo com Benjamin, o movimento operado pela escrita de Kraus era retroativo e aparentemente conservador, porém, tratava-se de uma prática progressista que se materializava em uma aparência cínica frente ao novo, e essa era para Benjamin a caracerística mais forte do trabalho de Kraus. Benjamin alude a uma prática de ataque da parte do escritor que teria por motivação trazer o objeto de volta à sua condição de origem, isto é, a um estado em que o objeto irradia indagaçóes a um sujeito que as recebe e elabora um sentido para elas, desdobrando essas indagações em novos problemas.

\footnotetext{
${ }^{3}$ Há uma edição recente do ensaio de Adolf Loss em português, Ornamento e crime, publicada pela editora Cotovia, de Lisboa, em 2004. As referências que farei aqui são da edição e tradução para o castelhano Adolf Loos: ornamentos y delito y otros escritos, traduzidos por Lourdes Cirlot e Pau Pérez, da Editorial Gustavo Gili, Barcelona, 1972.
}

* (BENJAMIN, Walter. "Karl Kraus". In: Gesammelte Schriften, Band II-1, Herausgegeben von Rolf Tiedmann. Frankfurt am Main: Suhrkamp Verlag, 1977: 336.) 
Quando se atenta para o título do o artigo "Negativo e ornamental: um poema de Carlito Azevedo em seus problemas", já se percebe logo no título que há a retomada mascarada de velhos debates, pois ao parafrasearem, sem citar, o título do ensaio de Adolf Loos que foi publicado na "ultra-avançada" Viena dos anos de 1908, os críticos literários autores do artigo sobre o poema de Carlito Azevedo fazem ecoar sentido e o efeito social do ensaio de Adolf Loos. ${ }^{4}$ $\mathrm{O}$ artigo dos críticos brasileiros desenha parcialmente o marco ao qual a análise proposta estaria circunscrita - um poema de Carlito Azevedo. No entanto, as ambições do artigo ultrapassam uma análise meramente textual e o leitor se depara com a arquitetura do julgamento de toda a poesia do poeta Carlito Azevedo e, por extensão, de toda a poesia que se pensa a si mesma como contemporânea. Tal pretensão do ensaio igualmente mimetiza os procedimentos do sistema de análise desenhado pela crítica marxista que exige que sua intervenção seja capaz de produzir um julgamento eficaz e funcional em relação a um ideal de totalidade. Tanto a arte como a poesia têm que funcionar na lógica de uma totalidade. Não se deve negligenciar o comentário de Theodor Adorno a respeito do ensaio de Loos. Quando publica o texto "Revendo o Surrealismo", em Notas de Literatura, ${ }^{5}$ confirma o preconceito contra o ornamento de Loos, dizendo que até surrealismo rejeitou o ornamento, e pensou-o a partir de uma negatividade. Entretanto, a própria sociedade já não queria mais pensar o negativo uma vez que os homens recusavam esta consciência negativa, e conclui, por isso, que até o Surrealismo tornou-se sem função. Há uma relação

\footnotetext{
${ }^{4}$ Os autores do ensaio apontam as características da poesia de Carlito Azevedo que os fazem julgá-la como ornamental e sem função ou, em suas palavras, negativa. "A autorreferencialidade, rebaixada a elemento entre outros de ourivesaria, obviamente perdeu o teor crítico - metalinguagem passa a significar produção de ilusão encadeada, mera componente de uma maquinaria neoesteticista de efeitos, sem compromisso de revelar os elementos materiais da figuração. Não mais exerce a função de criticar seu veículo e refletir sobre o fazer poético, pois agora compõe a retórica da imagem (ou da metáfora), valendo por um espetáculo verbal e conceitualmente prolífico de figuras e paramentaçôes sem fim. A tônica deixou de ser posta na desmontagem das imagens, ou nas interrupçóes autorreflexivas, porquanto a metalinguagem tornou-se instrumento para a produção de beleza dentro do programa esteticista do poema - programa que se formula, como em muita arte contemporânea, com os recursos sabotadores e críticos da beleza, os mesmos da vanguarda e da poesia moderna. Negatividade ornamental, pois." (SIMON, I. M.; DANTAS, V., op. cit.: 119).

${ }^{5}$ Agradeço à professora, crítica literária e poeta Masé Lemos pela lembrança do texto sobre o surrealismo de Theodor Adorno.
} 
de semelhança tanto de argumentação como de julgamento entre o ensaio de Loos, o julgamento de Adorno e o dos críticos brasileiros que salta aos olhos do leitor. Iumna Maria Simon e Vinícius Dantas têm razão quando indicam já na primeira frase de seu artigo que ainda está por fazer-se "uma história da intertextualidade na experiência recente da poesia brasileira em que se diferenciem as várias práticas de apropriação, glosa e crítica dos materiais da tradição. E tampouco se registrou como essas práticas se modificaram ao correr do tempo".* Pode-se dizer o mesmo com relação a essa prática na crítica literária, especialmente nos usos decalcados que se fazem no presente de debates antigos, e, com isso, torna-se urgente uma reflexão sobre a crítica neo-romântica e seus arquétipos. O espaço-tempo que nos separa do passado e do futuro, e que opera a distinção entre a glosa e o comentário do texto original, deveria ser o de assumir uma posição de se estar em jogo, de compreender que aquilo que deixamos para trás pode, por fatores de probabilidade e condições factuais, comprometer as práticas do presente e, do mesmo modo, que aquele que está à frente pode afetar o presente na sua impossibilidade mesma de alcance. Esse modo de operar vem da fórmula de Karl Kraus expressa na epígrafe a este artigo: "diferença, e que só essa diferença faz existir um espaço de manobra (Spielraum) para a cultura".* Transcrevo a citação em alemão porque o sentido dessa frase é fundamental para a compreensão do que se propõe como função da arte e de sua crítica: "ein Unterschied ist und daß in diesem Unterschied erst die Kultur Spielraum hat".*

O método empreendido pelos críticos Iumna Simon e Vinícius Dantas se assemelha em muito ao de Loos e Kraus na crítica direcionada aos produtores culturais de sua cultura e de seu tempo. Todos investem naquilo que poderíamos chamar de um "estilo polemista”, apresentam um mapeamento e uma análise radical, que agem de modo conservador, dos dados constatados. Em ambas as situações, tanto da "ultra-avançada" cultura da Viena dos anos de 1908 e 1909 como da poesia brasileira, também muito sofisticada em fins do século XX, trata-se de uma denúncia de falseamento do caráter avançado que os objetos analisados aparentemente apresentam. Os objetos são analisados por todos os críticos em questão como não tendo "função" na sociedade em que são produzidos. No entanto, não posso cobrar da relação que se estabelece entre essa tradição crítica a mesma coisa que eles cobram de seus objetos. Não
* (SIMON, Iumna Maria; DANTAS, Vinícius, op. cit.: 109)

* (KRAUS, Karl. Aforismos. Renato Zwick (trad.). Porto Alegre: Editorial Arquipélago, 2010: 169.)

* (KRAUS, Karl. "Die Zeit". In: Aforismen: Sprüche und Widersprüche; Pro domo et mundo; Nacht. Berlim, Directmedia, 2007.) 
* (LOOS, Adolf. Ornamentos y delito y otros escritos. Barcelona: Editorial Gustavo Gili, 1972: 44.)

irei buscar a constatação que eles são semelhantes em seus métodos e julgamentos, procuro justamente o espaço de manobra entre eles e que poderá permitir que encontremos nesse amontoado de cinzas algo de vivo para o tempo presente.

Em seu ensaio Ornamento e crime, o julgamento que Adolf Loos desfere contra os artistas do estilo Art Nouveau é taxativo, incontornável, absoluto e injusto. Venho tentando demonstrar nos últimos anos com meu trabalho de pesquisa sobre a "pervivência"6 na poesia de vanguarda brasileira e sul-americana que essa "pervivência" tanto do nosso passado colonial como da modernidade decadentista na modernidade sul-americana não impinge culpa alguma às vanguardas ou qualquer demérito à poesia moderna brasileira ou sul-americana. No entanto, no caso de Loos, a intenção era a de separar a arquitetura da arte por ser a arte, segundo o ensaísta, menos funcional e, portanto, menos útil, que a arquitetura (divisão esta que as artes aplicadas não cessavam de colocar em crise). Essa intenção estava fundamentada no argumento de que "Descubrí lo siguiente y lo comuniqué al mundo: la evolución de la cultura equivale a la eliminación del ornamento del objeto utilitário".*

Com seu ensaio, Loos inicia uma cruzada contra o ideal de obra de arte total ou o da cultura das belas artes. E seu argumento e consequente julgamento do Art Nouveau não poderiam ser mais injustos: associa o uso do ornamento ao crime. Isso se transformou em um lema da crítica modernista contra o decadentismo. Loos era um grande polemista e, juntamente com Karl Kraus, chegou a ser considerado pelos defensores da arte e da crítica funcionalista como verdadeiro guardião flagelador do impuro e do supérfluo. Claro que esses polemistas despertarão a atenção de Walter Benjamin, pois novamente tinha diante de si o argumento de que crítica e arte deveriam ser julgadas em instâncias separadas. Com isso, o que se observa é a formação de certos modelos da crítica, opera-

\footnotetext{
${ }^{6}$ Walter Benjamin desenvolve o conceito de pervivência, Das Fortleben, argumentando que há algo que faz com que alguns elementos ou as obras de arte mesmas sobrevivam para além da época que as viu nascer. O prefixo fort em alemão tem o sentido de indicar um movimento em direção a ou de passagem. No conceito de Fortleben, ou da "pervivência" da obra na memória coletiva, sobressaem as observaçōes sobre "transformação" (Wandlung) e sobre "renovação" (Erneuerung). A isso, Walter Benjamin chama o "pós-amadurar" (Nachreife) da linguagem da obra, segundo ele "um dos processos históricos mais fecundos". Cf. BENJAMIN, Walter. "A Tarefa do Tradutor". In: Clássicos da Teoria da Tradução. Werner Heidermann (org.). Florianópolis: UFSC, Núcleo de Tradução, 2001.
} 
dos ao longo de sua própria prática, que de algum modo negligenciam os aspectos históricos das demandas de seu tempo. Uma pergunta em clave histórica deve ser feita: o que o ornamento tem a dizer para a operação artística contemporânea? Ou ainda, o que o debate contra o ornamento produz na operação crítica e na operação com as formas artísticas?

Para Iumna Simon e Vinícius Dantas, a poesia de Carlito Azevedo é ornamental e negativa, vazia de conteúdo vivido, e na qual não se pode levar a sério nem mesmo sua caraterística mais forte constatada pelos críticos como sendo "a vertigem", pois a vertigem é uma metáfora erótica e o erotismo na poesia de Carlito Azevedo, ainda segundo os críticos, é produto de um "espetáculo textual gozosamente tatuado".*

Em Design and crime, and others diatribes (2002), Hal Foster comenta, em releitura histórica, a "cruzada" de Adolf Loos contra o ornamento na arquitetura. Num dos textos desse livro, "Design and crime", o crítico constrói uma rede de semelhanças entre o Style 1900 ou Art Nouveau e o que ele denomina de Style 2000 para fazer o leitor ouvir as novas ressonâncias de um velho debate. Foster relembra que o uso e a crítica ao ornamento não paracem ter ficado para trás e não estão muito longe de nossa época cultural. Entretanto, há diferenças e são essas diferenças que tornam o debate interessante para o presente. Foster destaca o modo de operar a cultura que girava em torno de um ideal de "obra de arte total", Gesamtkunstwerk, obra composta por meio das artes e ofícios, o que submeteu a arte a uma espécie de processo de indiferenciação entre subjetividade e "objetualidade" em que o artista se esforçava para imprimir sua subjetividade em todos os tipos de objetos mediante uma expressão vitalista, tendo com esse processo o desejo de resistir, de alguma maneira, ao avanço da reificação industrial. Adolf Loos, com sua austera prática da arquitetura, não acreditava, segundo Foster, que com o uso do ornamento se fosse capaz de "resistir" à reificação humana, tornando-se um grande crítico do hibridismo estético do Art Nouveau. A polêmica se instaurou motivada pelo achincalho produzido por Loos quando associa o estilo Art Nouveau a rabiscos de criança nas paredes e à pele tatuada de um "Papua". E ainda vaticinou do alto de sua moral dizendo que o estilo ornamental era erótico e degenerado, uma inversão do caminho correto da civilização e, portanto, deveria ser sublimado, separado e purificado.

* (SIMON, lumna Maria; DANTAS, Vinícius, op. cit.: 119.) 
* (FOSTER, Hal. Design and crime, and others diatribes, New York: Verso, 2002: 14.)

É possível encontrar um espaço de manobra entre o julgamento de Loos do erotismo decadentista do final do século XIX e o taxativo julgamento dos críticos brasileiros ao se referirem a uma poesia que não apresenta um erotismo original e verdadeiro? $\mathrm{Ou}$, ainda, que seu erotismo advidiria do recalque sublimador no uso discursivo da tradição? Nesse sentido, caberia mais uma vez perguntar: quando o erotismo não foi um uso discursivo e performático? Mas deixemos de buscar por origens e sistematizaçóes, porque esse debate poderia se repetir tantas vezes quisermos. Basta lembrar o que Mário de Andrade cobrou da poesia dos parnasianos brasileiros e também da poesisa de Oswald de Andrade: "faltava-lhes o lirismo".

De outra parte, seria interessante pensar como uma questão do passado volta a provocar crise e para tal deve ser repensada já em suas formulações iniciais, não tomando como dadas as conclusões que historicamente foram atribuídas a essas mesmas questôes em sua época, bem como nas épocas que a sucederam. No caso da crítica de Hal Foster ao conservadorismo polemista de Loos, a análise conclui que o modernismo propagou uma atitude reativa e inconteste contra o ornamento.

Este ditado anti-decorativo é um mantra modernista, se é que alguma vez houve um, e para o domínio puritano ele está inscrito em cada palavra que os pós-modernos usam, por sua vez, para condenar os modernistas como Loos. ${ }^{7 *}$

O crítico norte-americano dá ênfase crítica ao fato de que devemos encontrar algo nesse debate entre Loos e os modernos que retome essa mesma crise instaurada na modernidade ocidental, crise essa que nos constitui a todos nós enquanto modernos.

Mas talvez os tempos tenham mudado novamente; talvez estejamos em um momento em que as distinçōes entre as práticas possam ser revalorizadas ou refeitas - sem a bagagem ideológica da pureza e da propriedade anexadas a essas retomadas. ${ }^{8 *}$

A crítica de Iumna Simon e Vinícius Dantas guarda estreitas relaçôes com a prática crítica modernista opondo-se ao orna-

\footnotetext{
${ }^{7}$ No original: "This anti-decorative dictate is a modernist mantra if ever there was one, and it is for the puritanical propriety inscribed in such words that postmodernists have condemned modernists like Loos in turn."

${ }^{8}$ No original: "But maybe times have changed again; maybe we are in a moment when distinctions between practices might be reclaimed or remade - without the ideological baggage of purity and propriety attached."
} 
mento e, portanto, contra a não funcionalidade. Padece, assim, do mesmo problema modernista de não incluir a si mesma no quadro no qual o ornamento vicejaria. Ao não incluir a arte ornamental no âmbito da arte moderna, a crítica não inclui a si mesma no interior da crise, e emite seu julgamento situada em um lugar privilegiado, vale dizer, a partir de um exterior. As consequências de uma posição como essa conduzem o pensamento do e sobre o moderno para fora da crise que instaura a própria modernidade: a crise da linguagem, da representação e, por consequência, do legado a ser transmitido. Não produz dessa maneira o questionamento sobre aquilo que não cessa de não se inscrever, não cessa de escapar-nos: a de como lidar com a relação vital entre a crítica e a história do pensamento ocidental. Ou ainda: a de "como" prover de um sentido revolucionário a batalha da crítica contra a superficialidade e a banalidade na cultura na primeira década do século XXI? Entre o progressismo e o cinismo, há algum espaço de manobra que possa fornecer a possibilidade da existência de uma cultura?

Se há um processo de "retradicionalização" na poesia brasileira" iniciado na última década do século XX, mais do que a constatação do fenômeno, a tarefa da crítica é encontrar aquilo que Walter Benjamin reivindicava para toda a motivação crítica, isto é, descobrir e trazer novamente à vida o que pervive da faísca do vivo nas cinzas que restaram da combustão da história em seu sentido de transformação e amadurecimento.

Si, para usar una comparación, se quiere ver la obra en crecimiento como una hoguera en llamas, el comentarista está frente a ella como un químico; el crítico como un alquimista. Mientras que para aquél sólo quedan como objeto de su análisis maderas y cenizas, para éste sólo la llama misma conserva un enigma: el de lo vivo. Así, el crítico

\footnotetext{
${ }^{9}$ Em artigo já citado, "Condenados à tradição”, a professora Iumna Simon antecipa o julgamento que repetiria no artigo publicado na revista Novos Estudos, a respeito da poesia contemporânea brasileira. "O discurso da tradição tornou-se desse modo o fiador de um estado de normalidade contra a exceção anterior que, afinal, pôde ser controlada pela institucionalização progressiva, pelo oficialismo midiático e por um calculismo highbrow. Temos de sugerir que a poesia que escrevem está integrada a essa prática relutantemente crítica, que reverencia a tradição e se apropria dela, embora aqui e ali ambos possam temperar o paradigma retradicionalizador com os seus próprios interesses geracionais. Em Carlito Azevedo, o rigor construtivo vira esteticismo escancarado, um dispositivo de dissolução referencial e vertigem sintática que transpõe a contundência do cabralismo para um espetáculo de indeterminação textual movido pelo desejo de ornamento e beleza." (SIMON, Iumna Maria, op. cit.: 9)
} 
* (BENJAMIN, Walter. Dos ensayos sobre Goethe. Barcelona: Gedisa Editorial, 2000: 14) pregunta por la verdad, cuya llama viva sigue ardiendo sobre los pasados leños de lo que ha sido y las ligeras cenizas de lo vivido.*

Os críticos brasileiros em questão constatam um "movimento" em direção à "retradicionalização" da poesia. Partindo dessa constatação, a ação mais urgente a se empreender é a de ouvir criticamente o que nesse reacomodar de camadas, que é o terremoto da história, surge como uma voz que pode produzir a cultura, ou ainda, como na formulação de Kraus, o que cria a necessidade no ser humano de se movimentar e de viver nesse espaço de morte que é o passado. Tal atitude exige uma busca do crítico pelo espaço de manobra entre o tradicional e sua "retradicionalização", entre a morte e a vida, para que se possa compreender o sentido que essa ressonância devolve ao presente, ou seja, colocar em jogo, em movimento esse processo de reverência ao passado observado.

Se há a retomada, ou ainda, como proponho, se há a "pervivência" de elementos do passado na arte, e, portanto, na poesia contemporânea, esses elementos estão vivos. Esta sim é uma relação viva, porém residual, uma vez que eles subsistem enquanto faísca, enquanto possibilidade, entretanto têm outra razão de ser que não aquelas que tiveram em seus outros modos de vida. Se há uma opção pelo conceito de "pervivência" para ler os movimentos da cultura, claramente é em outro modo de entender a relação com a tradição que se posiciona. Walter Benjamin, para quem a relação com o passado era fundamental para ler o presente, compreendeu a "pervivência" - "das Fortleben": o viver em, o viver através - na relação que o texto resultante de uma tradução mantinha com o original. Escrito como prefácio às traduções para o alemão que Benjamin fizera de poemas de Charles Baudelaire, o ensaio no qual é desenvolvido o conceito de Fortleben é uma proposição clara da relação do escritor com o passado. Deve-se ressaltar aqui que o ensaio sobre a tarefa do tradutor foi escrito durante os mesmos anos nos quais Benjamin se dedicava a escrever sobre a função da crítica, ou seja, ao redor dos anos de 1916-1923, anos de preparação das traduçôes dos poemas de Baudelaire, de 1914-1915, quando escreve o ensaio sobre Hölderlin, e de 1919 quando foi terminada a primeira versão do ensaio sobre o livro As afinidades eletivas, ensaio cujo tema de investigação é, antes de tudo, a função da crítica como uma "busca autêntica" pela verdade. É interessante lembrar aqui também que é durante esses anos que Walter Benja- 
min trabalha na revolucionária pesquisa sobre o barroco. Entre seu esboço, em 1916, e sua versão final, em 1925, no livro Origem do drama barroco alemão observa-se a obsessão do crítico em elaborar um método anacrônico com o qual ele pudesse ler o seu presente mediante a análise da história a contrapelo. Benjamin estava muito interessado em compreender o expressionismo das primeiras décadas do século XX, para tal empreendeu uma tarefa de pesquisar o barroco enquanto uma teoria da linguagem na modernidade e tentar "medir" a intensidade e "modo de vida" de sua época frente a essa "pervivência".

Nessa aventura, a falta de autonomia característica da presente geração sucumbiu ao peso impressionante do Barroco, ao defrontar-se com ele. Somente em poucos casos a mudança de perspectiva que começou com o expressionismo, embora tenha sido afetada pela poética de Stefan George, levou a uma intuição capaz de descobrir novas e verdadeiras conexōes, não entre o crítico moderno e seu objeto, mas dentro do próprio objeto.*

Nesse sentido, não se trata de encontrar, nisso que alguns críticos denominam como teoria e prática neobarrocas, posiçôes transgressivas frente ao estabelecido ou formulações de experiências excluídas, ou, ainda, não se trata de criar um espaço para uma teoria não oficial da mestiçagem (o que quer que seja uma mestiçagem oficial). Retomar criticamente o problema do barroco é, segundo uma postura crítica produtiva, repensar o seu próprio objeto; não é estabelecer com ele uma relação de identidade, ou seja, entre crítico e objeto, é, ao contrário, descobrir nele novas e verdadeiras conexôes a ponto de redimensionar sua própria prática da linguagem. Uma teoria do barroco pensada como teoria da linguagem na modernidade não resulta necessariamente em composições transgressivas. Ademais, ser ou não transgressivo não se deve simplesmente à posição política de reconhecer ou não cânones e de manter ou não o devido respeito frente à tradição. Ser transgressivo é compreender-se como não lugar ou compreender o lugar como algo mais originário que o espaço. Se há algo fora de lugar nessa prática da linguagem é precisamente o de não haver o reconhecimento de "um" lugar, lugar privilegiado para observação, ou, ainda, seu movimento é em busca do lugar em que se vive a cisão entre palavra e referente, teoria essa já formulada por Michel Foucault em seu, não tão novo, porém, inesquecível estudo sobre a linguagem na modernidade: As palavras e as coisas. Há uma maneira de ler o barroco e o
* (BENJAMIN, Walter. Origem do drama barroco alemão. São Paulo: Brasiliense, 1984: 76, grifo meu.) 
neobarroco como uma reflexão filosófica e prática sobre a política da dominação, da soberania dos sujeitos, isto é, da sujeição voluntária, da autocensura como aberração inserida no coração do sistema e do próprio sentido dos laços sociais. Portanto, há mais coisas entre o barroco e nós do que nos fazem ver os outros modos de compreender o neobarroco. Além da transgressão há o horizonte de discussão daquilo que fundamenta e erige as relações sociais. Há uma discussão visceral, portanto, corporal sobre o poder.

$\mathrm{O}$ artigo de Iumna Simon e Vinícius Dantas constata que a escrita de Carlito Azevedo é altamente hedonista e caprichosa em suas idas e vindas, mas, se isso é um fato, não é porque essa poesia deseja continuar dentro de uma tradição, ou ainda, porque deseja evitar as inconsistências e inconsequências das práticas provocadoras. Ao contrário, o artista sabe que as épocas de decadência artística são épocas de "vontade" artística. Sabe que não pode inventar mais nada, por isso mimetiza o fazer artístico e o transforma em um "querer" artístico e é por isso que lê com dignidade a sua época, ele não tem a pretensão de ser um grande artista e tampouco de oferecer fórmulas ou formulações passíveis de se transformarem em um estilo transmissível: porque original, pessoal e fruto de experiência individual. $\mathrm{O}$ artista sabe que esses são os quesitos do cânone moderno, e isso permitiria a uma obra ser transmitida como legado. O termo "legado" em latim quer dizer "enviado". O enviado é aquele que está instituído do poder de dizer algo sobre sua época, seu ditado tornar-se-á apropriável, propriedade. Porém, ler e dizer algo com dignidade não quer dizer simplesmente compreender e, ao mesmo tempo, ser apropriado por sua época. Giorgio Agamben, em seu livro Idéia da prosa, escreve sobre a ideia de época criticando a obsessão do presente tempo em salvar, no sentido de resgatar, toda a cultura da barbárie instaurada pelo moderno, sem perceber que da barbárie somos todos coparticipantes. Essa operação de salvamento resulta no seu contrário: ao não querer perder a nova época que já chegou ou chegará, mesmo que seja a época da impossibilidade de ser uma época, perde-se a época. $O$ pensamento conservador, com isso, perde sua capacidade de admiração, de paixão pela possibilidade de recomeçar tudo desde o início.

E não há nada mais triste que o esgar com que, no meio do mal-estar geral, os mais espertos roubam aos seus semelhantes os seus próprios sofrimentos, mostrando-lhes que eles são apenas os hieróglifos, para 
eles próprios por enquanto indecifráveis, da nova felicidade dessa época. [...]

Em nossa obstinação de nos darmos tempo, perdemos o sentido deste dom, tal como, no nosso querer incessantemente tomar a palavra, é a própria razão da linguagem que perdemos.*

Para Agamben, o contemporâneo é aquilo que se pode entrever na temporalidade do presente é sempre retorno que não cessa de se repetir, e de nunca se inscrever, portanto, nunca funda uma origem e, com isso, aproxima-se da noção de poesia. Penso que é disso que se trata, quando se analisa em clave histórica o artigo de Iumna Simon e Vinícius Dantas. Ao não se dar conta de que crítica e poesia mantêm-se em vital relação com seu passado e que estão totalmente imbricadas com o seu presente, os críticos não se dão conta do espaço de manobra entre eles e sua tradição, perdem a capacidade ou a potência de admiração, de paixão pela possibilidade de recomeçar tudo desde o início, ou seja, pela possibilidade de poder dizer "de novo"; em outras palavras, não conseguem produzir a cultura justamente por não se colocarem em jogo nesse espaço de manobra.

Não há, portanto, como estabelecer qualquer tipo de relação com a tradição se são escolhidos a priori conceitos como o de criminalidade e de ornamental. A relação com o passado, como nos demonstra Walter Benjamin, é sempre de atraso e retenção. Num procedimento que mantém conexões com o pensamento barroco no sentido de uma teoria da linguagem na modernidade, pode-se afirmar que a entrada na temporalidade do presente é uma caminhada em direção a uma arqueologia daquilo que no presente não podemos viver e, "restando não vivido, é incessantemente relançado para a origem, sem jamais poder alcançá-la."*

Baltazar Gracián, talvez o mais instigante pensador do mundo barroco, discorre sobre arte na sua relação com os modos de vida. A arte pode ser pensada como produtora de um saber prático que antes de mais nada é também uma maneira de pensar as relações de e com o poder. Em $A$ agudeza e a arte do engenho, Gracián desenvolve sua noção de "arte sutil" como uma dobra da noção mesma de "reserva". Uma arte sutil requer uma dilação, uma hesitação e um atraso. $\mathrm{O}$ réten, a reserva, em todas as matérias sempre foi uma grande regra do viver, sobretudo o do viver com êxito, o que era uma questão de extrema importância para o pensador barroco. Nesse sentido, não há como concordar com a rejeição por parte do
* (AGAMBEN, Giorgio. A Idéia da prosa. João Barrento (trad.). Lisboa: Ed. Cotovia, 1999: 82.)
* (AGAMBEN, Giorgio. "O que é o contemporâneo?" In: O que é o contemporâneo? e outros ensaios. Vinícius Honesko (trad;). Chapecó: Ed. Unochapecó, 2009: 55.) 
* (SIMON, lumna Maria; DANTAS, Vinícius, op. cit.: 120)

*(Idem)

*(Idem)

* (Ibidem: 117.) artigo dos críticos brasileiros em questão de que a poesia de Carlito Azevedo não é neobarroca porque não é transgressiva, porque reafirma "a ilusão literária e refunda a literatice como pós-vanguardismo"; labor da sua tarefa de interrogar, formular e proferir o ditame da poesia na modernidade. A consequência disso é que visitar o passado como se ele estivesse disposto em prateleiras de um grande bazar de novidades antigas não tem o sentido de interrupção ou de negação da possibilidade de dizer. O problema do dizer não é um problema restrito ao poeta moderno; é, ao contrário, um problema da modernidade, da modernidade pensada enquanto crise - crise da linguagem, da representação e do tempo. Como problema instaurado nessa crise, o ornamento perde todo o sentido da imputação de um crime e se pensado como uma prática do viver do artista moderno perde a sua função de ornamento. Deixa de ser ornamental, não porque tenha elevado o nível do trabalho e sua prática da autoreferencialidade passasse a "revelar", como cobram os críticos de Carlito Azevedo, "os elementos materiais da figuração", ${ }^{*}$ também não deixa de ser uma impostura da negatividade porque, ainda como reprovam os críticos, "tenha deixado de se construir com os recursos sabotadores da beleza",* deixando de transformar assim o negativo em ornamental. O poema deixa de sofrer a imputação do crime da ornamentação porque tem que cumprir uma função, esta sim inexorável, a de obedecer ao ditame da poesia. E qual é esse ditame? O de escapar ao silêncio a que estamos todos os modernos condenados. Escapar ao caráter celebratório do poder instituído - venha ele de onde vier, seja ele quem seja - que a sociedade moderna imputou à poesia. E o modo de operar dessa poesia é o de fazer "girar em falso" a engrenagem da língua, fazendo com que um hino opere como uma elegia, na qual a perda cantada tradicionalmente no gênero não tenha o sentido propriamente de uma perda e sim de um anúncio da poesia "que vem", "que está vindo". Nesse sentido, os críticos de Carlito Azevedo não precisariam mais ficar preocupados porque constatam que a relação do poeta, "tal qual (n)outros poetas atuais, com a arte é quase sempre uma paráfrase de intenções (imaginadas ou documentadas)" seja uma relação meramente "temática" marcada por uma "graça pós-moderna, imaginemos, de fazer odes ou elegias para desenhos de Lichtestein ou glosar Rothko para dissertar sobre a efemeridade da vida".* Se compreendidos como manifestação e diálogo com a modernidade 
pensada enquanto "crise", essa relação deixa de ser meramente temática, para erigir-se como crítica ao presente que se instaura no coração mesmo da mitologia da época.

Escapar ao silêncio, escapar ao mito que nos funda de que não há mais nada a ser dito, essa é a tarefa da poesia e a da crítica hoje. O ditado da poesia é o de poder dizer novamente o sofrimento, só que maneira diferida, fazendo girar em falso a engrenagem autoritária e subordinadora da língua. É por isso que a poesia moderna "diz de novo". E para alguns, isso "soa" como ornamental, como desnecessário, como astúcia, ou como aposta em caminhos já trilhados e, portanto, mais fáceis, sem dificuldades, conforme apregoam Iumna Simon e Vinícius Dantas. Essa cobrança é decorrente de uma posição crítica que ainda tem na figura do "herói” a figura privilegiada do poeta. Reivindicação essa que pode ser encontrada no "antimodelo" de poeta constatado com a poesia de Carlito Azevedo:

Poesia marginal, Drummond, maneirismo, decadentismo, neobarroco, surrealismo, Cabral - todas essas referencias estão comprimidas de tal modo que ganhem indeterminação e cada uma delas se perca numa textualidade afetadamente estetizada, nefelibata quase diríamos, sugerindo que não há evolução de formas e o pluralismo é vitorioso. Tendo deixado de refletir a pressão da evolução de formas como processo superador em sentido estrutural, a tradição agora parece ser um patrimônio equânime e homogêneo, ao qual o intertextualista tem livre acesso a qualquer instante (justamente o oposto da arena de impedimentos, repressōes e proibições, que definem a vigência de uma tradição).*

Do modo como articulam os argumentos, os críticos parecem requerer mais um poeta e uma poesia que tenham a função de fazer evoluir as formas da arte (em que pese toda a discussão sobre a "forma" da arte empenhada no início deste texto), bem como a de "refletir a pressão da evolução como processo superador", e a de vencer na arena contra os conservadores os "impedimentos, repressões e proibições”, vitória esta que fará entrar em vigência uma outra tradição. Para os críticos, a poesia tem uma função e não uma tarefa. Uma perguntar merece ser aqui enunciada: a função de conservador e de revolucionário não assume com isso uma mera alternância de espaços? Ora instituídos, ora instituintes? O obedecer ao ditado ou ditame, tomado como tarefa da poesia, tem sempre uma disposição ao compartilhamento de experiências entre os que convivem na e produzem a cultura. O que se busca nesse pro- 
cesso é justamente o contrário desse niilismo ou má fé constatado. O que se busca é o poder dizer "de novo" a dor e com isso "ouvir" o sofrimento da cada um, esse poder dizer "de novo" é decorrente da crise instaurada pelo moderno. A tarefa da crítica não é cumprida - ao contrário, serve com isso ao niilismo - se ela opera o rapto dessa possibilidade de dizer "de novo".

Se a crítica literária brasileira constata que há um processo de "retradicionalização" na poesia atual e que essa "retradicionalização", como em outros julgamentos nos quais já se proferiu a sentença, não produz nada de novo ou de interessante na literatura contemporânea no Brasil, se a crítica literária denuncia, sem se sentir incluída, que essa tomada do passado como mercadoria ou como meio de distinção social produz uma literatura na qual se desenham palavras sem fundo, sem a contraparte do sentimento e emoção das quais elas deveriam ser consequência, há uma contraparte nesse quadro geral delimitado pela crítica que pode ser compreendido dentro de outros modos de socialização e criação de vínculos.

Não faz parte do horizonte de expectativa do artista contemporâneo a discussão sobre a função da tradição em sua obra, pois o passado para ele se oferece, como se oferece a todos nós, como um tempo cumprido, como um tempo dos mortos. Quem faz esse tipo de cobrança e desfere seus julgamentos implacáveis se a postura do artista/herói não condiz com o legado de transmissão da tradição é uma parte da crítica literária. A questão da arte e do artista é a de "como" viver, "como" inventar novos modos de vida frente à morte. "Como" descobrir a faísca do vivo no pedaço de carvão que resulta do processo histórico.

Para finalizar, exponho um relato de quem trabalha, há mais de 15 anos, o ensino e a crítica que se faz na universidade brasileira em relação com as concepções e práticas do ensino de literatura no ensino médio. Como parte das atividades que planejava e executava com meus alunos do curso de Letras na Universidade Federal de Santa Catarina, entre as quais convidava poetas para falarem com os alunos do ensino médio, convidei certa vez o poeta Carlito Azevedo, que aceitou prontamente meu convite, para uma palestra no Colégio de Aplicação da universidade. Entre as tantas perguntas que os alunos lhe fizeram e as tantas e quantas respostas que demonstravam aos alunos a vivência daquele poeta com a poesia, Carlito em uma de suas respostas a um aluno começou a falar do poema Un coup de dés, de Mallarmé, como um poema da ambiva- 
lência entre a coragem e a indecisão. Destacou a figura do capitão do navio, deste que, na função de herói do poema, deveria enfrentar o desafio de conduzir um navio em meio a uma tempestade e de, diante de toda essa dificuldade, tentar impedir que ele fosse a pique. O capitão do navio cogita todos os modos de rever a situação catastrófica, entre essas maneiras revisita em ritmo de partitura musical toda a tradição poética, todo o ditado da poesia a respeito da catástrofe. Desde a Odisseia até Las soledades passando também por Hamlet. O capitão cogita em lançar os dados, única ação que ele se permitiria, pois não abandonaria o navio, recorrendo a quem sabe uma configuração estelar capaz de, numa determinada conjunção, interferir no destino do navio e no dele. O capitão morreria e sem lançar os dados, afundaria juntamente com o navio, e seu gesto de simultânea indecisão e coragem - a última parte de seu corpo a afundar foi o braço esticado para cima e com a mão cerrada contendo dentro dela os dados - foi o gesto de alguém tocado pelo contemporâneo, ou seja, de alguém que empreendeu a tarefa de lidar, enfrentando-se com os mortos, com o incompreensível, o inapreensível e o enigmático de sua época.

Antes de terminarmos a conversa de Carlito Azevedo com os alunos, pedi a ele que lesse seu poema "Fractal", poema do acidente que também revisita todo o ditado da poesia a respeito da catástrofe. O poeta preferiu ler o poema "Sobre uma fotonovela de Felipe Nepomuceno", também um poema do acidente, e o leu em ritmo de partitura musical, com tons dramáticos, pois há outras vozes que compõem a circunstância do acidente. "Mas como o poema ia crescendo, $[. .$.$] "* e o poeta não parou no final do último verso escrito$ e continuou lendo o poema sem parar, estabelecendo um tipo de comunicação sonora com os ouvintes a partir da repetição infinita dos versos do poema. O que se repetia ali? Certamente que não eram meros fonemas que eram repetidos. A repetição daqueles "sons" era a possibilidade de um "dizer de novo" a dor de todos simultaneamente a um "escutar" de novo o sofrimento de cada um.

Quando saímos todos do auditório do colégio, um menino se aproximou e dirigiu-se a Carlito Azevedo: "Professor, professor", disse o menino. "Como é mesmo o título daquele poema do cara que morre com a mão fechada sem lançar os dados?", Carlito permaneceu mais uns vinte minutos conversando com o menino. Havia ali algo a ser dito e algo a ser escutado. Tratava-se do ditado da poesia. Com isso, não se quer dizer que a comunicação entre eles
* (AZEVEDO, Carlito. "Sobre uma fotonovela de Felipe Nepomuceno". In: Versos de Circunstância. Rio de Janeiro: Moby Dick Ed., 2001: 7 .) 
* (AGAMBEN, Giorgio, op. cit., 1999: 82.) estabelecida e os laços sociais ali criados são referentes aos temas da adolescência e que os poetas de hoje têm emoções de garotos. Repito a citação de Agamben:

E não há nada mais triste que o esgar com que, no meio do mal-estar geral, os mais espertos roubam aos seus semelhantes os seus próprios sofrimentos, mostrando-lhes que eles são apenas os hieróglifos, para eles próprios por enquanto indecifráveis.*

Contudo, que fique dito: a poesia de Carlito Azevedo não é a poesia brasileira, bem como este texto não é representativo da crítica de poesia no Brasil de hoje. São apenas tentativas, um "fazer" motivado pela "vontade" artística.

Susana Scramim é professora de Teoria Literária da Universidade Federal de Santa Catarina, bolsista de Produtividade em Pesquisa nível 2 do $\mathrm{CNPq}$, Coordenadora do Núcleo de Pesquisa em Estudos Literários e Culturais - NELIC/ UFSC. É doutora em Teoria Literária e Literatura Comparada pela Universidade de São Paulo. Pós-Doutorado na Universidad de Sevilla, em 2005. Professora Visitante no Talen en culturen van Latijns Amerika (Departamento de Estudos de Cultura Latino-americana), da Leiden Universiteit, na Holanda, em 2007. É autora do livro de ensaios de crítica literária Literatura do Presente (Argos, 2007) e do livro Carlito Azevedo, para a coleção Ciranda de Poesia (EdUERJ, 2010). Organizou e preparou a coletânea de ensaios de Giorgio Agamben O que éo contemporâneo? e outros ensaios (Argos, 2009) e Enigmas. Egipcio, barroco, neobarroco na sociedade e na arte, de Mario Perniola (Argos, 2009).

E-mail: <sscramim@uol.com.br> 